\title{
Formação de toxinas durante o processamento de alimentos e as possíveis conseqüências para o organismo humano
}

\author{
Toxin formation during food processing and \\ possible consequences to the human body
}

Anne y Castro MARQUES 1

Tessa Bitencourt VALENTE ${ }^{1}$

Cláudia Severo da ROSA ${ }^{2}$

\section{RE S U M O}

A produção de alimentos envolve inúmeras reações químicas, durante as quais podem ser geradas substâncias tóxicas ao organismo humano. A produção destas substâncias pode ocorrer de diferentes maneiras, variando em quantidade e em grau de toxicidade. Este trabalho objetivou estudar a produção de toxinas no processamento de alimentos, assim como as conseqüências da ingestão dessas substâncias para o ser humano. O estudo foi realizado a partir de extensa pesquisa bibliográfica. As principais reações na formação de compostos tóxicos apresentadas no decorrer do estudo são: degradação de lipídios, hidrogenação, pirólise e defumação. Entre as substâncias formadas, destacam-se: peróxidos, ácidos graxos trans, aminas heterocíclicas e hidrocarbonetos aromáticos policíclicos. O profissional nutricionista necessita conhecer como ocorre a formação de toxinas durante os variados processamentos que envolvem alimentos, assim como os riscos para a saúde de quem consome essas substâncias. Também é preciso propor técnicas de processamento adequadas, visando ao bem-estar do consumidor e à manutenção das propriedades nutricionais do alimento.

Termos de indexação: Nutricionista. Produção de alimentos. Reações químicas. Substâncias tóxicas.

A B S T R A C T

Food production involves innumerable chemical reactions that may generate substances that are toxic to the human body. These substances can be produced in different ways, in varying amounts and degree of toxicity. The objective of this study was to investigate the production of toxins during food processing, as well as the

\footnotetext{
1 Mestrandas, Universidade Federal de Santa Maria, Programa de Pós-Graduação em Ciência e Tecnologia de Alimentos. Av. Roraima, 1000, Prédio 42, Campus Universitário, Camobi, 97105-900, Santa Maria, RS, Brasil. Correspondência para/Correspondence to: A.C. MARQUES. E-mail: <annezita@gmail.com>.

2 Centro Universitário Franciscano. Santa Maria, RS, Brasil.
} 
consequences of their ingestion. This study was based on extensive literature research. The main reactions leading to toxic compounds are: lipid degradation, hydrogenation, pyrolysis and smoking. Some of the formed substances are: peroxides, trans fatty acids, heterocyclic amines and polycyclic aromatic hydrocarbons. Dietitians need to know how toxins form during the various foods processing methods, as well as their health risks for consumers. It is also necessary to propose processing techniques that ensure the consumer's wellbeing and retain the nutritional properties of the food.

Indexing terms: Nutritionist. Food production. Chemical reactions. Toxic substances.

\section{N T R O D U ÇÃ O}

A produção de alimentos envolve inúmeras reações químicas, dentre as quais muitas ainda são desconhecidas. Mesmo assim, sabe-se que, durante tais reações, substâncias tóxicas ao organismo humano podem ser formadas ou podem ter sua toxicidade intensificada, de modo que se torna indispensável atentar para a relação entre o consumo dessas substâncias por longos períodos e o desenvolvimento de neoplasias que acometeram cerca de 10400000 norte-americanos em $2002^{1}$.

Com o objetivo de conhecer a formação de toxinas na produção de alimentos, assim como de oferecer um alimento nutritivo que não traga riscos ao comensal, optou-se por pesquisar a influência do processamento de alimentos na formação de substâncias tóxicas, observando-se também os efeitos do consumo destas substâncias para o organismo humano.

\section{Produção de substâncias tóxicas}

A produção de substâncias tóxicas nos alimentos pode ocorrer de diferentes maneiras, mas se dá especialmente quando os produtos são submetidos a altas temperaturas ${ }^{2}$.

Algumas das principais reações na formação de compostos tóxicos são a hidrogenação de gorduras, a oxidação lipídica e a pirólise. Entre os processamentos, destaca-se a defumação e entre os diversos produtos formados, são relevantes as nitrosaminas, os peróxidos, os ácidos graxos trans (AGT), os hidrocarbonetos aromáticos policíclicos (HAP) e as aminas heterocíclicas (AH). Cada substância apresenta toxicidade característica, causando maior ou menor dano à saúde, dependendo da dose, do tempo e da freqüência de exposição e das vias de absorção.

Entre as doenças associadas às substâncias tóxicas formadas durante o processamento de alimentos, destaca-se o câncer. As neoplasias malignas têm seu desenvolvimento influenciado direta ou indiretamente pela qualidade e tipo do alimento, assim como pelo emprego de métodos inadequados de preparo e de conservação dos produtos alimentícios ${ }^{3}$.

\section{Substâncias formadas a partir da degradação de lipídios}

A degradação de óleos e gorduras pode ocorrer por oxidação, hidrólise, polimerização, pirólise e absorção de odores e sabores estranhos. Dentre essas possibilidades, a oxidação é a principal causa de deterioração de lipídios, alterando várias propriedades do alimento, como qualidade sensorial, valor nutricional, funcionalidade e toxicidade, mudanças essas que podem ocorrer em várias etapas do processamento, como produção e armazenamento ${ }^{4-5}$.

Mais de 400 compostos químicos diferentes já foram identificados em óleos reutilizados. Os produtos de degradação costumam ser divididos em voláteis e não-voláteis, os quais permanecem no alimento e causam as alterações referidas anteriormente ${ }^{6-7}$.

A oxidação de lipídios, que ocorre quando o oxigênio é adicionado ou o hidrogênio ou elétrons são removidos da molécula, tem sido arduamente estudada devido à relação com a alteração de alimentos, com a produção de diversas substâncias, assim como pelas várias reações 
com outros constituintes dos alimentos. Sabe-se que essas reações podem ser modificadas por muitos fatores, como a presença de metais, enzimas (lipoxigenase, oxidases e lipases), antioxidantes, luz, pH, temperatura, oxigênio e peróxidos ${ }^{8-10}$.

A velocidade de oxidação depende do grau de insaturação do ácido graxo, ou seja, quanto maior o número de duplas ligações, maior a suscetibilidade à reação. Um exemplo é o óleo de soja, cuja estabilidade é menor que a da gordura de $\operatorname{coco}^{7,10,11}$.

A auto-oxidação lipídica é baseada em mecanismos que envolvem radicais livres. Peróxidos são formados a partir da reação de ácidos graxos insaturados e triglicerídios com o oxigênio e da conseqüente formação dos radicais livres, em uma etapa denominada iniciação. Posteriormente, o número de produtos gerados aumenta, assim como a produção de aldeídos (etapa de propagação), responsáveis pelo odor característico da rancificação. Ao final (etapa de terminação), os substratos lipídicos tornam-se escassos, ocorrendo reações entre os próprios radicais livres ${ }^{7}$. Outras substâncias que podem ser geradas durante o processo de auto-oxidação são álcoois, ácidos, hidrocarbonetos e cetonas ${ }^{4}$. A rancificação oxidativa é responsável, principalmente, pelas alterações organolépticas dos produtos alimentícios ${ }^{10-12}$.

Os peróxidos não são prejudiciais ao organismo humano, e sim os seus derivados. Uma das maneiras pelas quais os peróxidos podem ser formados é por meio da ação da enzima lipoxigenase sobre os ácidos graxos poliinsaturados linoléico e linolênico. A lipoxigenase é encontrada em hortaliças, frutas e em alimentos de origem animal. Exemplos de grãos ricos em lipoxigenases são soja, ervilha e algumas variedades de feijão ${ }^{6,7}$. Íons metálicos como ferro, cobalto, cobre e molibdênio podem atuar como catalisadores da decomposição dos peróxidos ${ }^{13}$.

No aquecimento excessivo das gorduras, como na fritura de alimentos, formam-se produtos tóxicos ou cancerígenos, entre os quais acroleína e peróxidos. Isso ocorre porque temperaturas elevadas aceleram os processos oxidativos e de degradação dos lipídios. No processo de fritura, três componentes são responsáveis pelas mudanças ocorridas na estrutura dos lipídios: umidade do alimento (promove hidrólise dos triglicerídios), contato do óleo ou gordura com o oxigênio (promove alterações oxidativas) e alta temperatura do processo, de, aproximadamente, $180^{\circ} \mathrm{C}$. Deve-se ter cuidado, portanto, com a produção de alimentos fritos por imersão sem o controle da qualidade do óleo ou da gordura vegetal nos estabelecimentos de alimentação coletiva ${ }^{14,15}$.

Desde 1997, a indústria de fast food vem adotando métodos para tentar controlar a qualidade e prolongar o tempo útil do óleo utilizado para fritura de imersão. Entre as medidas, incluem-se o uso de filtros ativos e passivos, antioxidantes e a própria manutenção dos equipamentos de fritura. Essas alternativas até podem prolongar a vida útil do óleo, contudo os produtos alimentícios absorvem igualmente grandes quantidades de lipídios degradados durante o processo ${ }^{6}$.

A decomposição de óleos e gorduras é diminuída se o processo de fritura for realizado com pequena quantidade de gordura, em panelas altas e estreitas, diminuindo o contato com o oxigênio. Além disso, o processo de rancificação pode ser diminuído se o óleo for guardado em recipientes de vidro ou de plástico e não ficar exposto à luz ${ }^{15-17}$. Deve-se também ter cuidado para que, durante os processos que utilizam aquecimento, a temperatura do óleo vegetal não ultrapasse os $170^{\circ} \mathrm{C}$, já que em temperaturas mais elevadas ocorrem a emissão de fumaça e o início dos processos oxidativos. É importante retirar os resíduos alimentares liberados durante a fritura, assim como certificar-se de que não haja detergente ou materiais de limpeza no recipiente no qual o óleo será aquecido ${ }^{6,18}$. No momento em que qualquer alteração for detectada no óleo utilizado para fritura de imersão, o produto deverá ser descartado.

A desidratação de alimentos é um procedimento utilizado para impedir a proliferação de 
microorganismos, no entanto níveis de umidade abaixo de $a_{w}<0,1$ tornam o produto suscetível à oxidação pela concentração de metais e pela formação de radicais livres no processo de secagem $^{10}$. O processo utilizado para impedir a oxidação da gordura do leite integral em pó, por exemplo, é envolver os glóbulos de gordura com uma camada de lactose, impedindo o contato direto com o $\mathrm{ar}^{4,13}$.

Hur et al. ${ }^{10} \mathrm{e}$ Chung et al. ${ }^{16}$ sugerem que a ingestão dos compostos formados a partir da oxidação em lipídios possa causar doença gástrica crônica e câncer. Outro ponto de grande relevância é que a oxidação do colesterol é considerada arterogênica e carcinogênica, aumentando o risco de desenvolvimento de dislipidemias e de doenças cardiovasculares.

\section{Ácidos graxos trans}

Os ácidos graxos insaturados (AGI) apresentam uma ou mais duplas ligações, podendo formar isômeros geométricos. Quando os hidrogênios ligados ao carbono da insaturação estão do mesmo lado o ácido graxo é denominado cis, quando os hidrogênios estão em lados opostos é denominado trans ${ }^{19-24}$.

Na natureza, os ácidos graxos geralmente estão na configuração $\operatorname{cis}^{20}$. Quando os ácidos graxos cis ou os triglicerídios que os contêm são submetidos a processos enzimáticos, oxidativos ou de hidrogenação, há a formação da configuração trans $^{21-22}$. Os ácidos graxos trans são sólidos à temperatura ambiente, com ponto de fusão mais elevado, podendo ser considerados intermediários entre os AGI e os ácidos graxos saturados $(\mathrm{AGS})^{23-24}$.

Os AGT sempre compuseram a dieta humana via ingestão de alimentos provenientes de animais ruminantes, como leite e carne bovina, pois são formados a partir de sistemas enzimáticos da flora microbiana, por meio do processo denominado biohidrogenação. Atualmente, essas substâncias encontram-se amplamente difundidas na dieta alimentar, como em margarinas, óleos vege- tais, produtos de confeitaria e panificação e alimentos fritos. Os alimentos que contêm gordura parcialmente hidrogenada contribuem com 80 a 90\% da ingestão diária de AGT; já no caso dos que contêm óleos refinados, a contribuição é entre 1 e 1,5\%, aumentando os níveis com a reutilização do óleo $19,20,22-25$.

Ovesen et al. avaliaram o perfil de gorduras utilizadas por duas grandes redes de fast food, encontrando altas concentrações de $A_{G}{ }^{23}$. No entanto, há divergência sobre a importância dos alimentos fritos como fonte de isômeros trans ${ }^{26}$.

A hidrogenação é um processo de endurecimento pelo qual o hidrogênio desfaz a insaturação e ocasiona a formação de AGT. O processo ocorre na presença de um catalisador de níquel, tendo como objetivos reduzir o grau de insaturação, para diminuir a velocidade de oxidação, e modificar as características físicas, como textura e ponto de fusão ${ }^{12}$. Os óleos vegetais são hidrogenados seletivamente, conservando o máximo de quantidade de ácido oléico e linolênico, fazendo com que a solidificação ocorra a temperaturas muito baixas, tornando-o praticamente inodoro e insípido, além de poder ser aquecido a $180^{\circ} \mathrm{C}$. Nas margarinas, a hidrogenação ocorre até que se alcance a cremosidade ou a dureza desejada ${ }^{19,24-27}$.

Quanto mais sólida a gordura de origem vegetal após o processo de hidrogenação, maior será a concentração de AGT. Estratégias como a combinação de hidrogenação parcial e interesterificação química reduzem significativamente a quantidade de $A G T$, sem alterar consideravelmente a relação ácido graxo poliinsaturado (AGS). Já a interesterificação enzimática tem permitido a produção de margarinas livres de isômeros $\operatorname{trans}^{19,28}$.

Os ácidos graxos trans, apesar de não possuírem efeito cumulativo, podem ser encontrados em vários tecidos do organismo humano, como, por exemplo, no tecido adiposo. Também passam de mãe para filho por meio do leite e da placenta e interferem na conversão de ácidos graxos essenciais a ácidos graxos poliinsaturados no organismo, 
sendo responsáveis por reações alérgicas, como a asma em adolescentes $24,29,30$.

No princípio dos anos 1990, estudos demonstraram que o consumo de isômeros trans altera as concentrações séricas de lipídios, aumentando o lipoproteína de baixa densidade (LDL colesterol) e diminuindo o lipoproteína de alta densidade (HDL colesterol), sendo, por estes motivos, associado ao aumento no risco de doença arterial coronariana $(D A C)^{20,28}$. Além disso, outros fatores relacionados ao consumo de AGT podem levar ao desenvolvimento de DAC: aumento dos níveis de lipoproteína(a) e de triglicerídios séricos; efeitos adversos no metabolismo de ácidos graxos essenciais e no balanço das prostaglandinas (há inibição da enzima delta-6-dessaturase), podendo levar à trombogênese (elevação dos marcadores de inflamação e disfunção endotelial, favorecendo a formação de placas ateroscleróticas). A morte súbita e a resistência à insulina são outras conseqüências possíveis $25-28,31,32$.

Há controvérsias sobre as mudanças metabólicas ocasionadas pelos AGT quando presentes em maior quantidade na nutrição humana ${ }^{23}$. $\mathrm{O}$ meio acadêmico vem discutindo constantemente sobre as vantagens e desvantagens da substituição de alimentos fontes de AGT pelos ricos em AGS. Os AGS, embora ricos em colesterol, não trariam alterações no HDLc, ao contrário dos trans que diminuíram HDLc além de elevarem LDLc ${ }^{24}$.

Estudos em cobaias demonstraram que os AGT competem com os ácidos graxos n- 6 e n-3 nas reações de dessaturação e elongação, produzindo eicosanóides sem atividade biológica. Os AGT também podem inibir as enzimas $\beta 5$ e $\beta 6$ dessaturase, bloqueando o metabolismo de ácidos graxos essenciais. Esses processos, durante a fase gestacional, podem alterar o desenvolvimento intra-uterino pela inibição da síntese de ácido araquidônico e docosahexaenóico (DHA) ${ }^{19}$.

O elevado consumo de alimentos ricos em $A G T$, além das implicações nutricionais, leva à redução da ingestão de ácidos graxos essenciais, como o ácido araquidônico (essencial para o crescimento e desenvolvimento dos tecidos) e o DHA (importante para a função visual e neural), favorecendo o desenvolvimento de síndromes causadas pela deficiência destes ácidos graxos ${ }^{19,24,33}$.

A busca por alternativas para produzir gordura vegetal hidrogenada sem isômeros trans demonstra a preocupação com o consumo desse composto. O Brasil, contudo, ainda não apresenta dados exatos sobre a ingestão de AGT, apesar de ser sabido que a utilização de gordura hidrogenada é ampla e indiscriminada, apontando, portanto, para um consumo elevado ${ }^{19}$.

Segundo Sanhueza et al. ${ }^{33}$ o ácido linoléico conjugado ou vacênico (trans do linoléico formado a partir da biohidrogenação em ruminantes que se alimentam de pasto) possui estrutura diferenciada, sendo apontado como possível substância anti-câncer, anti-aterosclerose, anti-obesidade e como modulador da imunidade. O tema ainda causa polêmica no meio científico, e alguns autores levantam a hipótese de que animais alimentados com pouca pastagem e com ração rica em sementes oleaginosas, apesar do alto teor de lipídios insaturados, em vez de produzirem o ácido vacênico produzem ácidos graxos trans em níveis significativos, contaminando a carne, o leite e derivados destes $20-25,32-34$.

Em um estudo de coorte realizado com mulheres saudáveis ( $n=80$ ), estimou-se que as substituições de $5 \%$ da energia proveniente dos ácidos graxos saturados e $2 \%$ proveniente dos ácidos graxos trans por ácidos graxos poliinsaturados podem reduzir o risco de doenças cardiovasculares para 42 e $53 \%$, respectivamente ${ }^{35}$.

Em julho de 2003, a Food and Drug Administration (FDA) decretou que, a partir de $1^{\circ}$ de janeiro de 2006, fabricantes de alimentos e de suplementos deveriam passar a listar, separadamente dos AGS, o conteúdo de AGT nos rótulos dos alimentos. Deste modo, atualmente todo alimento contendo mais de $0,5 \mathrm{~g}$ de ácidos graxos trans precisa especificar essa quantidade no rótulo ${ }^{36}$. No Brasil, o prazo para a adequação dos rótulos terminou em $1^{\circ}$ de julho de 2006 , conforme regulamentado pela $\operatorname{RDC} n^{\circ} 360$, de 23 de 
dezembro de 2003, aprovada pela Agência Nacional de Vigilância Sanitária (ANVISA) ${ }^{37}$.

Segundo a IV Diretriz Sobre Dislipidemias e Prevenção da Aterosclerose, 2007 não há consenso em relação à quantidade máxima permitida na dieta, no entanto, recomenda-se que a ingestão de gordura trans deva fornecer menos do que $1 \%$ da energia total da dieta ${ }^{38}$.

\section{Aminas heterocíclicas}

As aminas heterocíclicas (AH) são substâncias indesejadas produzidas durante a exposição de alimentos a altas temperaturas. Muitas AH são formadas ao assar, fritar ou cozinhar alimentos por longo período, principalmente os ricos em proteínas, como carnes e pescados ${ }^{39-41}$. As $\mathrm{AH}$ ainda podem ser encontradas em resíduos de panelas e em extratos de carne. Sua formação ocorre pela pirólise de certos aminoácidos, entre os quais triptofano, lisina, ácido glutâmico e fenilalanina, ou pela reação entre creatina (também denominada creatinina) e os produtos da Reação de Maillard ${ }^{42}$.

Investigações sobre a presença de $\mathrm{AH}$ foram realizadas em carne de boi (assada e frita) e carne de pescado (assado, no forno e a la parrilla) comercializadas na Espanha. Nas peças foram encontrados os seguintes mutágenos: 2-amino-3-metilimidazol (4,5-f) quinolina (IQ), 2-amino-3,4-dimetilimidazol (4,5-f) quinolina (MelQ) e 2-amino-3,8-dimetilimidazol $(4,5 f)$ quinoxalina $(\mathrm{MelQx})^{9}$

Balogh et al. ${ }^{43}$ analisaram tortinhas de carne bovina moída fritas em três temperaturas diferentes $\left(175^{\circ} \mathrm{C}, 200^{\circ} \mathrm{C}\right.$ e $\left.225^{\circ} \mathrm{C}\right)$ por 6 e $10 \mathrm{mi}$ nutos de cada lado, a fim de que fossem determinadas as condições de maior formação de aminas heterocíclicas. As maiores concentrações foram geradas na fritura a $225^{\circ} \mathrm{C}$ por 10 minutos/lado. Foram encontradas em maior quantidade PhIP e MelQx. A vitamina E, quando usada na concentração de $1 \%$ e adicionada diretamente sobre as tortinhas de carne moída diminuiu as quantidades de $\mathrm{AH}$, com médias de redução de 45 a 75\%.
As AH encontram-se entre as substâncias mutagênicas conhecidas mais potentes, causando tumores em animais de experimentação, principalmente na bexiga ${ }^{44}$. As aminas heterocíclicas são metabolizadas pelo citocromo P-450 dos microssomos hepáticos em mutágenos ativos, as $\mathrm{N}$-hidroxilaminas, as quais são convertidas em compostos capazes de se unir à guanina, afetando a replicação e a transcrição do DNA ${ }^{42,45,46}$.

Atualmente vem sendo analisada a correlação entre a ingestão de $\mathrm{AH}$ e a incidência de câncer de mama, cólon e próstata. Em animais, as aminas heterocíclicas provocam neoplasias malignas em glândulas mamárias, próstata, pulmão, cólon, pele, pâncreas, bexiga e fígado. Ainda há evidências de que elas afetam o sistema vascular, as glândulas salivares e de que levam à degeneração miocardial. Entretanto, é importante salientar que cada organismo reage de maneira específica, tolerando maiores ou menores doses desses compostos $^{42-48}$.

Para diminuir a formação desses compostos, deve-se adicionar antioxidantes naturais ou sintéticos durante a cocção, por estarem os intermediários dos radicais livres envolvidos na reação. Tanto a proteína de soja concentrada como a farinha da semente de algodão sem gordura contêm compostos antioxidantes que reduzem a mutagenicidade de $\mathrm{AH}$ na carne bovina cozida. Estatisticamente, a vitamina $\mathrm{E}$ e a essência de alecrim também possuem efeito positivo na inibição do PhIP, entretanto tratamento algum ou dose foram eficientes para inibir totalmente a formação das aminas heterocíclicas. Também é possível diminuir a produção das AHs no hambúrguer com a adição de cebola na carne bovina triturada crua ${ }^{43,48,49}$.

No microondas, apesar das temperaturas elevadas, a mutagenicidade das aminas heterocíclicas é reduzida pelo menor tempo de cocção. É preferível, portanto, processar alimentos à base de carne no microondas do que por meio de frituras ou cocção direta ${ }^{43}$.

Não foram encontrados na literatura valores de referência sobre o consumo diário tolerável de 
aminas heterocíclicas em seres humanos. Mesmo assim, a correta quantificação das aminas heterocíclicas nos alimentos preparados é essencial para avaliar os riscos para seres humanos².

\section{Hidrocarbonetos aromáticos policíclicos}

Os hidrocarbonetos aromáticos policíclicos são substâncias amplamente distribuídas no ambiente, formados principalmente em processos de combustão e pirólise de matérias orgânicas, como carvão e petróleo ${ }^{50,51}$, constituindo um grupo considerado altamente carcinogênico ou genotóxico ${ }^{52}$.

Além da pirólise, acredita-se que o processo de pirossíntese também esteja envolvido na produção dos hidrocarbonetos aromáticos policíclicos. Na pirólise, em temperaturas elevadas, compostos orgânicos são convertidos em moléculas pequenas não estáveis. Na pirossíntese, essas e outras sustâncias são recombinadas e produzem moléculas maiores e mais estáveis de HAP52.

São quatro as fontes principais de HAP em alimentos: fontes naturais (como queimadas em florestas), poluição ambiental (contaminação de solo e de água), materiais de embalagens e alguns tipos de processamento. Entre os processamentos de alimentos em que ocorrem produção de HAP incluem-se defumação, secagem direta com madeira ou carvão (churrasco e parrillada, por exemplo) e torrefação $0^{50,53}$.

Durante o processo de assar a carne na brasa, a gordura é pirolisada pela ação da chama direta na peça, assim como pelo calor do carvão, gerando os HAP carcinogênicos. Os hidrocarbonetos aromáticos policíclicos, que passam a compor a fumaça gerada, são absorvidos e se depositam na camada mais externa da carne. A concentração de HAP varia de acordo com as quantidades de gordura e de fumaça, mas pode alcançar valores de até 50ppm de benzo(a)pireno (BaP). Além do churrasco, essas substâncias já foram encontradas em embutidos, hambúrgueres, frango, peru, pescados, bacon e cebola submetidos a este tipo de tratamento culinário ${ }^{9,51,52}$.
Em um estudo realizado por Kazerouni et al. ${ }^{54}$ nos Estados Unidos, os maiores níveis de benzo(a)pireno (acima de 4ng de BaP/g de carne cozida) foram encontrados em carnes, hambúrguer e frango com pele grelhados ou assados em altas temperaturas. Cereais e hortaliças também podem ser fontes dietéticas de HAP, quando submetidos a processos de desidratação ${ }^{51}$.

No processo de torrefação, um dos alimentos que se destaca pela produção de HAP é o grão de café. Apesar de somente 20 a 30\% dos hidrocarbonetos aromáticos policíclicos da quantidade presente no pó passarem para a bebida, o modo de preparo pode aumentar a concentração no líquido. Quando o pó de café é fervido juntamente com a água (hábito ainda comum no Brasil), a quantidade de HAP é muito próxima à quantidade existente no pó. No entanto, quando o café é coado por processo direto, a liberação de HAP para a bebida diminui 5,5 vezes, se comparada ao pó fervido com a água. Foi demonstrado também que, além do modo de preparo facilitar a liberação de HAP para o café líquido, a cafeína aumenta a solubilidade do $\mathrm{B}(\mathrm{a}) \mathrm{P}$ em água pela formação do complexo benzo(a)pireno-cafeína, arrastando o B(a)P e demais HAP para a bebida. A quantidade de cafeína no café fervido com a água é até $30 \%$ maior do que no café coado diretamente. Portanto, a fervura facilita a passagem de hidrocarbonetos para a bebida pela maior liberação de cafeína e pela formação do complexo benzo(a)pireno-cafeína ${ }^{53}$.

Outra bebida amplamente consumida no Rio Grande do Sul que contém grandes quantidades de HAP é o chimarrão. Isso se deve ao fato de que a erva-mate (Ilex paraguarensis) ainda é beneficiada rudimentarmente, com a etapa de sapecação das folhas feita com chama de combustão direta. Machado et al. encontraram no chimarrão níveis de até $0,22 \mu \mathrm{g}$ de $\mathrm{B}(\mathrm{a}) \mathrm{P}$ nos primeiros $250 \mathrm{~mL}$ da bebida, valor excedente em 90 vezes o limite máximo permitido para água pura pela legislação brasileira ${ }^{53}$.

Em relação à concentração de $\mathrm{HAP}$, foi realizado um estudo sobre a quantidade de hidro- 
carbonetos aromáticos policíclicos em margarinas, cremes vegetais e em maioneses, por serem os óleos e as gorduras a segunda fonte de HAP. Margarinas e cremes vegetais, apesar da pequena quantidade de HAP, são considerados fontes importantes, devido à sua ampla utilização na dieta. Em geral, produtos contendo óleo de milho mostram em sua formulação maiores níveis de contaminação ${ }^{55}$. A contaminação dos óleos vegetais se dá pela poluição do ar e pela conseqüente deposição de partículas sobre as plantas oleaginosas, devido ao fato de as plantas absorverem HAP em solos contaminados e pela sapecação do grão em fumaça produzida pela queima de madeira. Conclui-se, portanto, que a produção de HAP em alimentos contendo óleo vegetal ocorre pela contaminação da matéria-prima, assim como durante o processamento dos grãos ${ }^{56}$.

Em um experimento realizado para quantificar os valores existentes de HAP em diversos grupos de alimentos, as maiores concentrações de hidrocarbonetos aromáticos policíclicos foram encontradas no grupo dos açúcares e doces (chocolates, gelatinas e alcaçuz), destacando-se o criseno $(36 \mu \mathrm{g} / \mathrm{kg})$. Esse dado foi considerado surpreendente, já que até o momento nenhum desses produtos era suspeito de conter altos níveis de HAP ${ }^{57}$. No Brasil, análises realizadas em amostras de açúcares comerciais indicaram a presença de HAP em concentrações que variam de 0,25 a $0,83 \mu \mathrm{g} / \mathrm{kg}^{52}$.

O mecanismo de toxicidade dos HAP se dá pela formação de produtos intermediários reativos, responsáveis pelos efeitos carcinogênicos ${ }^{58}$. Segundo a Organização Mundial da Saúde, dentro dos grupos de HAP, 13 compostos são claramente carcinogênicos e genotóxicos ${ }^{59}$. São metabolizados pelas enzimas hepáticas em diol-epóxidos, ligando-se covalentemente às macromoléculas celulares (incluindo o DNA) e causando erros de replicação e mutações. Há evidências de que outras reações intermediárias também são geradas por um processo de oxidação, o que pode resultar em instabilidade química na alquilação do DNA, levando ao processo mutagênico?
Estudos epidemiológicos associam a exposição de misturas de HAP contendo benzo(a)pireno ao risco aumentado de produzir câncer de pulmão e outros tumores. Também foi observada maior freqüência de câncer de estômago em populações que consomem tradicionalmente grandes quantidades de produtos cárneos defumados ${ }^{54,58}$. A World Cancer Research Fund desaconselha a preparação de carnes a temperaturas elevadas ou expostas diretamente ao fogo por aumentar o risco de câncer no estômago e no trato gastrointestinal ${ }^{3}$.

Além disso, animais de experimentação expostos ao B(a)P por diferentes vias de introdução e administração, incluindo a dieta por via oral, têm desenvolvido papilomas e carcinomas gástricos $^{60}$. Segundo o Comitê Científico de Alimentação Humana da União Européia, são considerados cancerígenos os seguintes HAP: benzo(a)antraceno, benzo(b)fluoranteno, benzo(j)fluoranteno, benzo(k)fluoranteno, benzo(g,h,i)perileno, benzo(a)pireno, criseno, ciclopenta(c,d)pireno, dibenzo(a,h)antraceno, dibenzo(a,e)pireno, dibenzo(a,i)pireno, dibenzo(a,l)pireno, ideno(1,2,3-cd) pireno e 5-metilcriseno ${ }^{61}$.

A necessidade de estabelecimento de limites para HAP em alimentos tem sido manifestada por vários países, sendo este tema considerado prioritário dentro do Comitê do Codex Alimentarius para Aditivos Alimentares e Contaminantes (CCFAC) ${ }^{62}$. O Brasil ainda não estabeleceu tais valores máximos. Por outro lado, Alemanha, Áustria e Polônia limitam em $1 \mu \mathrm{g} / \mathrm{kg}$ o teor máximo de $\mathrm{B}(\mathrm{a}) \mathrm{P}$ em carnes defumadas, sendo esse valor utilizado como referência para os demais alimentos ${ }^{55}$. O Comitê Científico da Alimentação Humana da Comunidade Européia considera que, sabendo-se do efeito genotóxico dos HAP, seus níveis nos gêneros alimentícios devem ser tão reduzidos quanto razoavelmente possíveis. Além disso, dadas as incertezas que ainda existem quanto aos níveis aceitáveis de HAP nos alimentos, o Regulamento (CE) n 466/2001 da Comissão prevê uma revisão das medidas até primeiro de abril de $2007^{61}$.

Muitos alimentos industrializados com sabor e aroma de defumados têm a defumação 
direta substituída por líquidos com menor risco para a saúde humana, mesmo que alguns preparados ainda contenham certa quantidade de hidrocarbonetos aromáticos policíclicos ${ }^{63}$. Além disso, o Comitê Científico da Alimentação Humana indica a utilização de carvão ativado para remover benzo(a)pireno durante a refinação de óleos ${ }^{61}$. É necessário então que a indústria alimentícia e os Estados invistam em pesquisas e novas tecnologias para diminuir a produção destas substâncias durante o processamento de alimentos.

\section{CONSIDERAÇÕ ES FINAIS}

Verificou-se, durante a realização deste estudo, que a química de alimentos e seus processos ainda são pouco conhecidos cientificamente. Não se sabe se hábitos tidos como comuns durante a preparação de uma refeição podem causar algum dano a quem a consome. Observou-se também que, dependendo do alimento e do tipo de preparação, substâncias tóxicas podem ser formadas, em níveis variados, assim como cada organismo tolera maior ou menor ingestão, provocando ou agravando doenças.

Assim, é importante que o profissional nutricionista tenha conhecimento sobre a produção de toxinas durante os vários processos envolvendo alimentos, bem como que saiba em que níveis aquelas podem afetar a saúde humana. É necessário, também, conhecer e propor técnicas de processamento adequadas, visando à saúde do cliente e à manutenção das propriedades nutricionais do alimento.

Muitos estudos ainda necessitam ser realizados nesse campo, tanto pela dificuldade em confirmar suspeitas, como pela grande variedade de alimentos e pelas diversas formas de prepará-los existentes.

\section{OLA B OR A ÇÃ O}

A.C. MARQUES participou na elaboração do projeto de pesquisa, na coleta de referencial teórico, na discussão dos resultados e na elaboração do artigo. T.B. VALENTE participou na coleta de referencial teórico, na discussão dos resultados e na elaboração do artigo. C.S. ROSA participou na elaboração do projeto de pesquisa e na elaboração do artigo.

\section{REFERÊ NCIAS}

1. National Cancer Institute. SEER Cancer Statistics Review, 1975-2002. 2006 [cited 2007 Aug 21]. Available from: <http://seer.cancer.gov/csr/1975_ 2002/sections.html>.

2. Knize MG, Kulp KS, Salmon CP, Keating GA, Felton James $\mathrm{S}$. Factors affecting human heterocyclic amine intake and the metabolism of PhIP. Mutat Res. 2002; 506-7:153-62.

3. Garófolo A, Avesani CM, Camargo KG, Barros ME, Silva SRJ, Taddei JAAC, et al. Dieta e câncer: um enfoque epidemiológico. Rev Nutr. 2004;17(4): 491-505.

4. Araújo JMA. Química de alimentos: teoria e prática. 2a.ed. Viçosa: UFV; 1999.

5. Hidalgo F, Nogales F, Zamora R. The role of amino phospholipids in the removal of the cito-and geno-toxic aldehydes produced during lipid oxidation. Food Chem Toxicol. 2007;46(1):43-8.

6. Paul S, Mittal GS. Regulating the use of degraded oil/fat in deep-fat/oil food frying. Food Sci Nutr. 1997; 37(7):637-62.

7. Varlet $V$, Prost $C$, Serot $T$. Analitycal, nutritional and clinical methods volatile aldehydes in smoked fish: analysis methods, occurence and mechanisms of formation. Food Chem. 2007; 105:1536-56.

8. Abott TP, Wohlman A, Isbell T, Momany FA, Cantrell C, Garlotta DV, et al. 1,3-di(3-Methoxybenzyl) thiourea and related lipid antioxidants. Ind Crops Prod. 2002; 16(1):43-57.

9. Wong DWS. Química de los alimentos: mecanismos y teoría. Zaragoza: Acríbia; 1995.

10. Hur SJ, Park GB, Joo ST. Formation of cholesterol oxidation products (COPs) in animal products. Food Control. 2007; 18(8):939-47.

11. Benjakul S, Visessanguan W, Phongkanpai V, Tanaka M. Antioxidative activity of caramelisation products and their preventive effect on lipid oxidation in fish mince. Food Chem. 2005; 90(1-2): 231-9.

12. Bobbio PA, Bobbio FO. Química do processamento de alimentos. 3a.ed. São Paulo: Varela; 2001.

13. Souza TC. Alimentos: propriedades físico-químicas. 2a.ed. Rio de Janeiro: Cultura Médica; 2001. 
292 | A.C. MARQUES et al.

14. Laguerre M, Lecomte J, Villeneuve P. Evaluation of the ability of antioxidants to counteract lipid oxidation: existing methods, new trends and challenges. Prog Lipid Res. 2007; 46(5):244-82.

15. Saguy IS, Dana D. Integrated approach to deep fat frying: engineering, nutrition, health and consumer aspects. J Food Engin. 2003; 56(2): 143-52.

16. Chung MJ, Kang AY, Park SO, Park KW, Jun HJ, Lee SJ. The effect of essential oils of dietary wormwood (Artemisia princeps), with and without added vitamin $E$, on oxidative stress and some genes involved in cholesterol metabolism. Food Chem Toxicol. 2007; 45(8):1400-9.

17. Proudlove K. Os alimentos em debate: uma visão equilibrada. São Paulo: Varela; 1996.

18. Coenders A. Química culinária: estudio de lo que les sucede a los alimentos antes, durante y después de cocinados. Zaragoza: Acríbia; 2001.

19. Martin CA, Matshushita M, Souza NE. Ácidos graxos trans: implicações nutricionais e fontes na dieta. Rev Nutr. 2004; 17(3):361-8.

20. Chardigny JM, Malpuech-Brugère $C$, Dionisi $F$, Bauman DE, German B, Mensink RP, et al. Rationale and design of the TRANSFACT project phase I: a study to assess the effect of the two different dietary sources of trans fatty acids on cardiovascular risk factors in humans. Contemp Clin Trials. 2006; 27(4):364-73.

21. Sauer LA, Blask DE, Dauchy RT. Dietary factors and growth and metabolism in experimental tumors. J Nutr Biochem. 2007; 18(10):637-49.

22. Geibler C, Brede O, Reinhardt J. Cis-transIsomerization of unsaturated fatty acids during $\gamma$-irradiation of barley grains. Radiat Phys Chem. 2003; 67(2):105-13.

23. Sanibal EAA, Mancini Filho J. Perfil de ácidos graxos trans de óleo e gordura hidrogenada de soja no processo de fritura. Ciênc Tecnol Alimentos. 2004; 24(1):27-31.

24. Semma M. Trans fatty acids: properties, benefits and risks. J Health Sci. 2002; 48(1):7-13.

25. Katan MB. Regulation of trans fats: the gap, the polder, and McDonald's French fries. Atherosclerosis. 2006; 7(2):63-6

26. Romero A, Cuesta C, Sánchez-Muniz FJ. Trans fatty acid production in deep fat frying of frozen foods with different oils and frying modalities. Nutr Res. 2000; 20(4):599-608

27. Harnack L, Lee S, Schakel SF, Duval S, Luepker V, Arnett DK. Trends in the trans-fatty acid composition of the diet in a metropolitan area: The Minnesota Heart Survey. J Am Diet Assoc. 2003; 103(9):1160-6.
28. Seppänen-Laakso T, Laakso I, Hiltunen R. Analysis of fatty acids by gas chromatography, and its relevance to research on health and nutrition. Anal Chim Acta. 2002; 465(1-2):39-62.

29. Institute of Medicine. Dietary references intakes for trans fatty acids. [cited 2005 Oct 8]. Available from: <http://www.lom.edu/report.asp?id=540>.

30. Innis SM. Trans fatty intakes during pregnancy, infancy and early childhood. Atheroscl Suppl. 2006; 7(2):17-20.

31. Lopez-Garcia E, Schulze MB, Meigs JB, Manson JE, Rifai N, Stampfer MJ, et al. Consumption of trans fatty acids to plasma biomarkers of inflammation and endothelial dysfuncion. J Nutr. 2005; 135(3): 556-61.

32. American Dietetic Association. Position of the American Dietetic Association and Dietitians of Canada: dietary fatty acids. J Am Diet Assoc. 2007; 107(9):1599-611.

33. Sanhueza JC, Nieto SK, Valenzuela AB. Ácido linoléico conjugado: un ácido graso com isomeria trans potencialmente beneficioso. Rev Chil Nutri. 2002; 29(2):98-105.

34. Santos FL, Silva MTC, Lana RP, Brandão SCC, Vargas LH, Abreu LR. Efeito da suplementação de lipídios na ração sobre a produção de ácido linoléico conjugado (CLA) e a composição da gordura do leite de vacas. Rev Bras Zootecnia. 2001; 30(6):1931-8.

35. Gylling $H$, Miettinen T. A review of clinical trials in dietary interventions to decrease the incidence of coronary artery disease. Curr Control Trials Cardiovas Med. 2001; 2(3):123-8.

36. Food and Drug Administration. Revealing trans fats. FDA Consum. Magazine [e-journal]. 2003 [cited 2005 Oct 1]; 37(5). Available from: <http:// www.fda.gov/fdac/features/2003/503_fats.html>.

37. Brasil. Ministério da Saúde. Agência Nacional de Vigilância Sanitária. Resolução RDC n³60, de 23 de dezembro de 2003. Aprova regulamento técnico sobre rotulagem nutricional de alimentos embalados, tornando obrigatória a rotulagem nutricional. [acesso em 2008 abr 15]. Disponível em: $<$ http://elegis.anvisa.gov.br/leisref/public/showAct. php? id $=9059 \&$ word $=>$.

38. Sociedade Brasileira de Cardiologia. IV Diretriz Brasileira Sobre Dislipidemias e Prevenção da Aterosclerose. Departamento de Aterosclerose da Sociedade Brasileira de Cardiologia. Arq Bras Cardiol. 2007; 88:1-18.

39. Delfino RJ, Sinha R, Smith C, West J, White E, Lin $\mathrm{HJ}$, et al. Breast câncer, heterocyclic aromatic amines from meat and $\mathrm{N}$-acetyltransferase 2 genotype. Carcinogenesis. 2000; 21(4):607-15. 
40. Viberg P, Wahlund KG, Skog K. On-line capillary based quantitative analysis of a heterocyclic amine in human urine. J Chromatogr A. 2006; 1133(1-2): 347-52.

41. Gross GA, Grüter A. Quantitation of mutagenic/ carcinogenic heterocyclic aromatic amines in food products. J Chromatogr A. 1992; 592(1-2):271-8.

42. Felton JS, Knize MG, Wu RW, Colvin ME, Hatch FT, Malfatti MA. Mutagenic potency of food-derived heterocyclic amines. Mutat Res. 2007; 616(1-2): 90-4.

43. Balogh Z, Gray JI, Gomaa EA, Booren AM. Formation and inhibition of heterocyclic aromatic amines in fried ground beef patties. Food Chem Toxicol. 2000; 38(5):395-401.

44. Ahn JH, Kim YP, Seo EM, Choi YK, Kim HS. Antioxidant effect of natural plant extracts on the microencapsulated high oleic sun ower oil. J Food Eng. 2008; 84(2):327-34.

45. Keating GA, Bogen KT, Chan JM. Development of a meat frequency questionnaire for use in diet and cancer studies. J Am Diet Assoc. 2007; 107(8): 1356-62.

46. Braceló-Barrachina E, Moyano E, Galceran MT, Lliberia LL, Bagó B, Cortes MA. Ultra-performance liquid chromatography-tandem mass spectrometry for the analysis of heterocyclic amines in food. J Chromatogr A. 2006; 1125(2):195-203.

47. Kobayashi M, Hanaoka T, Tsugane S. Validity of a self-administered food frequency questionnaire in the assessment of heterocyclic amine intake using 2-amino-1-methyl-6-phenylimidazo[4,5b]pyridine (PhIP) levels in hair. Mutat Res. 2007; 630(1-2):14-9.

48. García-Closas R, García-Closas M, Kogevinas M, Malats N, Silverman D, Serra C, et al. Food, nutrient and heterocyclic amine intake and the risk of bladder cancer. Eur J Cancer. 2007; 43(11): 1731-40.

49. Tomaino A, Cimino F, Zimbalatti V, Venuti V, Sulfaro $V$, de Pasquale $A$, et al. Influence of heating on antioxidant activity and the chemical composition of some spice essential oils. Food Chem. 2005; 89(4):549-54.

50. Camargo MCR, Tfouni SAV, Vitorino SHP, Menegário TF, Toledo CF. Determinação de hidrocarbonetos policíclicos aromáticos (HPAS) em guaraná em pó (Paullina cupana). Ciênc Tecnol Aliment. 2006; 26(1):230-4.

51. Grainger J, Huang W, Patterson Jr DG, Turner WE, Pirkle J, Caudill SP, et al. Reference range levels of polycyclic aromatic hydrocarbons in the US population by measurement of urinary monohydroxy metabolites. Environ Res. 2006; 100(3):394-423.
52. Bettin SM, Franco DW. Hidrocarbonetos policíclicos aromáticos (HPAs) em aguardentes. Ciênc Tecnol Aliment. 2005; 25(2):234-8.

53. Camargo MCR, Toledo MCF. Chá-mate e café como fontes de hidrocarbonetos policíclicos aromáticos (HPAs) na dieta da população de Campinas. Ciênc Tecnol Aliment. 2002; 22(1):49-53.

54. Kazerouni N, Sinhá R, Hsu CH, Greenberg A, Rothman N. Analysis of 200 food items benzo[a] pyrene and estimation of its intake in an epidemiologic study. Food Chem Toxicol. 2001; 39(5):423-36.

55. Camargo MSFO, Toledo MCF. Hidrocarbonetos aromáticos policíclicos em margarinas, creme vegetal e maionese. Ciênc Tecnol Aliment. 2000; 20(1): 51-5.

56. Camargo MSFO, Toledo MCF. Efeito do processamento na contaminação de óleo refinado de milho por benzo(a)pireno. Braz J Food Technol. 1998; 1(1-2):97-106.

57. De Vos RH, Van Dokkun W, Schouten A, De Jong-Berkhout P. Polycyclic aromatic hydrocarbons in dutch total diet samples (1984-1986). Food Chem Toxicol. 1990; 28(4):263-8.

58. Falahatpisheh MH, Kerzee JK, Metz RP, Donnelly KC, Ramos KS. Inducible cytochrome P450 activities in renal glomerular mesangial cells: biochemical basis for antagonistic interactions among nephrocarcinogenic polycyclic aromatic hydrocarbons. J Carcinog. 2004; 3(1):12.

59. World Health Organization. Summary and conclusions of the sixty-fourth meeting of the joint FAOMHO Expert Committee on Food Additives. Rome: WHO; 2005.

60. Midio AF, Martins DI. Toxicologia de alimentos. São Paulo: Varela; 2000.

61. Comunidade Européia. Recomendação da Comissão de 4 de fevereiro de 2005 relativa à investigação suplementar dos teores de hidrocarbonetos aromáticos policíclicos em determinados gêneros alimentícios. Jornal Oficial da União Européia; Bruxelas. 2005. p.34-43.

62. Codex Alimentarius Comition. Action required as a result of changes in acceptable daily intake (ADI) status and other toxicological recommendations. The Hague; 2005. p.6.

63. Rollan MG. Alimentación humana: errores y sus consecuencias. Madrid: Mundi-Prensa; 1990.

Recebido em: 25/1/2007

Versão final reapresentada em: 16/5/2008 Aprovado em: 11/7/2008 